\title{
THE REASONS OF THE VERNACULAR ARCHITECTURE FOR THE REGULATION OF CONTEMPORARY INTERVENTIONS. TWO EXAMPLES OF RURAL ARCHITECTURE ON DANUBE DELTA AND THE VESUVIUS
}

\author{
P. De Joanna ${ }^{1,}$ *, A. M. Dabija ${ }^{2}$, A. Passaro ${ }^{1}$, G, Vaccaro $^{1}$, R. Sfinteș ${ }^{2}$ \\ ${ }^{1}$ DiARC Federico II University of Naples - (dejoanna, passaro)@unina.it, giuseppe.vaccaro@ hotmail.it \\ ${ }^{2}$ CSAU, "Ion Mincu” University of Architecture and Urbanism in Bucharest - (am.dabija, r.sfintes)@uauim.ro
}

\author{
Comission II - WG II/8
}

KEY WORDS: Heritage, Valorization, Identity

\begin{abstract}
:
The development and growth of the territory has for centuries been conditioned by the availability of resources on site. The minor architecture which is presented as a vast and varied repertoire of unique architectural forms, perfected over time to meet the needs of living places, is the repository of the formal and cultural testimonies that represent the integration between man and environment, which took place in a constant process of adaptation and enhancement of limits and resources in terms of climate, materials, soil morphology and geology. The "not only formal" result of this growth process is a consolidated iconography that summarizes the profound reasons for building through techniques developed according to the characteristics of the available materials and the needs of life and daily work, an absolute synthesis between form and function that gives rise to the repertoire of the lexicon of the architecture of a place and of the landscape. Starting from these reflections, the proposed study seeks to investigate the reasons for the constructive lexicon of some examples of vernacular architecture related to different contexts, identifying the reasons for the constructive choices in terms of relationships between the function of technical elements and construction characteristics; the purpose of this approach is to regulate constructive interventions in consolidated settlements of vernacular architecture by proposing a study methodology that highlights the rules and reasons for those constructive choices so that purely formal distortions and misunderstandings do not occur in current practices. The selected case studies are the rural settlements of Terzigno, a municipality in the province of Naples (Italy) on the slopes of Vesuvius and some of the rural settlements in the Danube Delta, in Romania.
\end{abstract}

\section{THE DANUBE DELTA REGION}

\subsection{Settlement characters}

The Danube Delta is a region in the South-Eastern part of Romania, in Dobrogea. It is an area of land and water, of ancient mountains (around 300-400 million years ago, compared with the Alps or Carpathians, 'only' 60 million years old), of forests and steppes, with milder temperatures compared to the rest of Romania (influenced by the Black Sea) but with harsh, strong winds.

At the mouth of the Black Sea and between the Danube channels, there has always been a commercial and social exchange between the local population and the navigators on the Black Sea coming from the other shores or from the Mediterranean Sea. An area of ancient road crossings - from the North Sea to the Black Sea and from here to the Mediterranean or from the Russian steppe to Constantinople - it is the homeland of no less than 18 different ethnical groups: Romanians, Aromanians, Bulgarians, Turks, Tatars, Gypsies, Jews, Greeks, Armenians, Russians, Lipovans, Ukrainians, Gagauzians, Germans, Italians, Albanians, Serbs, Hungarians and others. In a way, it can be considered a land of geographic and cultural and diversity.

Known in history as Scytia Minor, this region was populated by Dacians but ruins from the Greek and Roman antiquity are witnesses of the commercial relations and cultural exchanges. It was part of the Roman Empire. Furthermore, it is the territory where Apostle Andrew preached (who is considered the protector of Romania). Migrating populations leave traces in Dobrogea, in the first Anno Domini centuries.

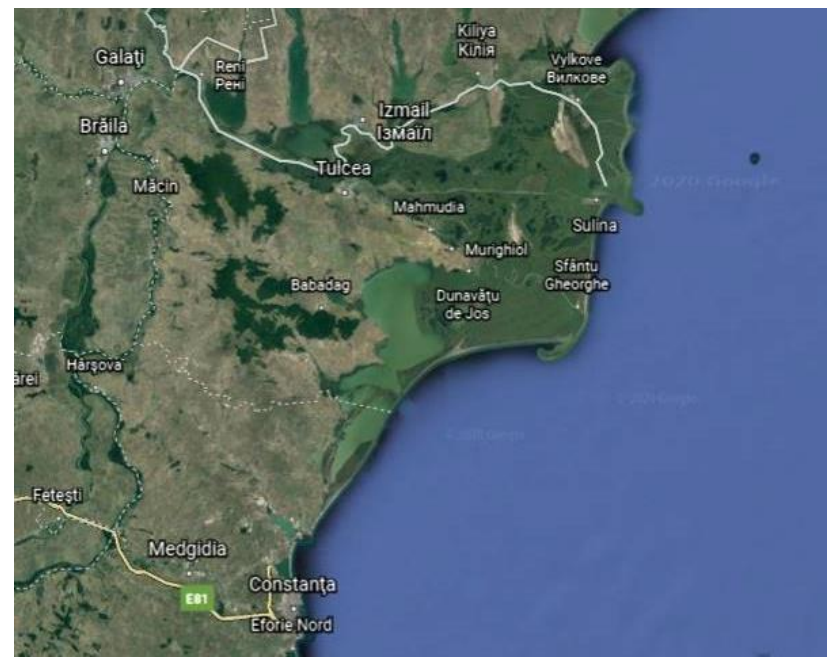

Figure 1. The Danube Delta with the Razim and Babadag lagoons, separated from the Black Sea by sand dunes. Google Earth capture.

At the border of the Otoman Empire, it is periodically lost and conquered. As the sand-line advanced and separated the land from the sea, one of the ancient and medieval citadels - Enisala

\footnotetext{
* Corresponding author
} 
(built by the ancient Greek as Herakleia, held by the Genovese in the XVth Century as holders of the navigation monopoly on the Black Sea and by the Otomans as Yeni-Sale as part of their empire, lost and conquered by Walachia, Bulgaria, Russia...) was abandoned and ruined by the passing of the time (Figure 2).

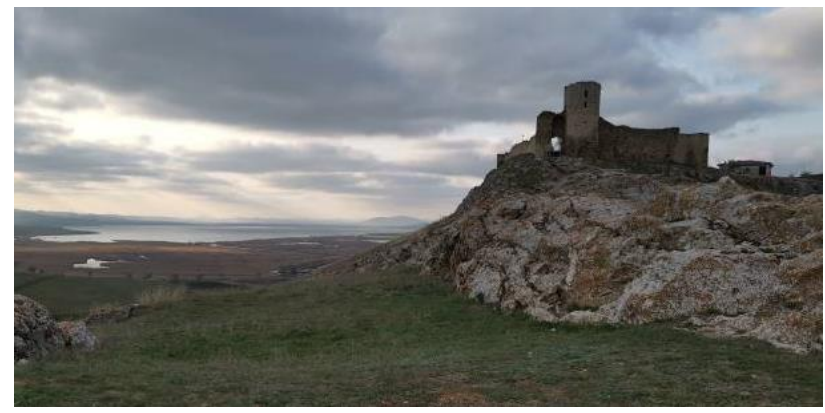

Figure 2. The Enisala citadel, facing the Babadag lake.

\subsection{Resources}

In this land of the steppe, ruled by earth, wind and water, the natural building materials are the most common for houses: adobe walls, lifted on stone foundations, covered with thatched roofs on wooden structures. In fact, the most available materials: stone, clay, reeds and wood.

Durable buildings have been erected of course, in stone, as the ancient ruins of Histria, Callatis, Tomis, Capidava or Herakleia are witnesses but the scope of this paper is to analyse the residential stock of the vernacular patrimony.

The local stone is represented by gray, blue-ish and pink granite, slates, tuff as well as a rich range of beautiful multicoloured and multipatterned limestone. Wood was provided from the nearby forests, protected in this area, with a managing legislation (Codul Silvic, 2016). Clay is used in adobe buildings or, in burned forms as barrel tiles. Brick masonry is seldom used in the buildings of Dobrogea (Stanculescu et al., 1957).

Reeds grow in and near the chain of lagoons that separate the land from the Black Sea (Figure 3).

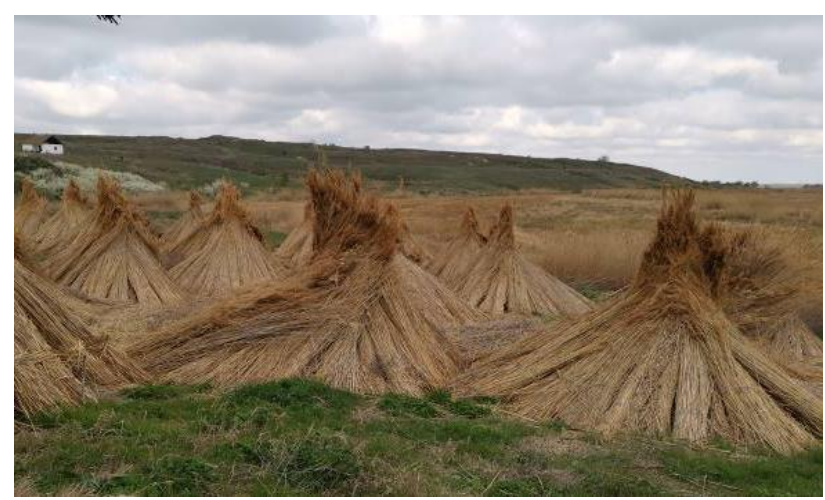

Figure 3. Reeds, harvested from the Razim lagoon banks.

\subsection{Rural space layout}

The Sarichioi village, bordering the Razim lake, is characterized with lanes parallel to the lake, unified by perpendicular lanes that lead to the lake, allowing the locals to reach the lake and the boat in the shortest time After all, they are fishermen settlements and their access to the lake is vital (Figure 4).

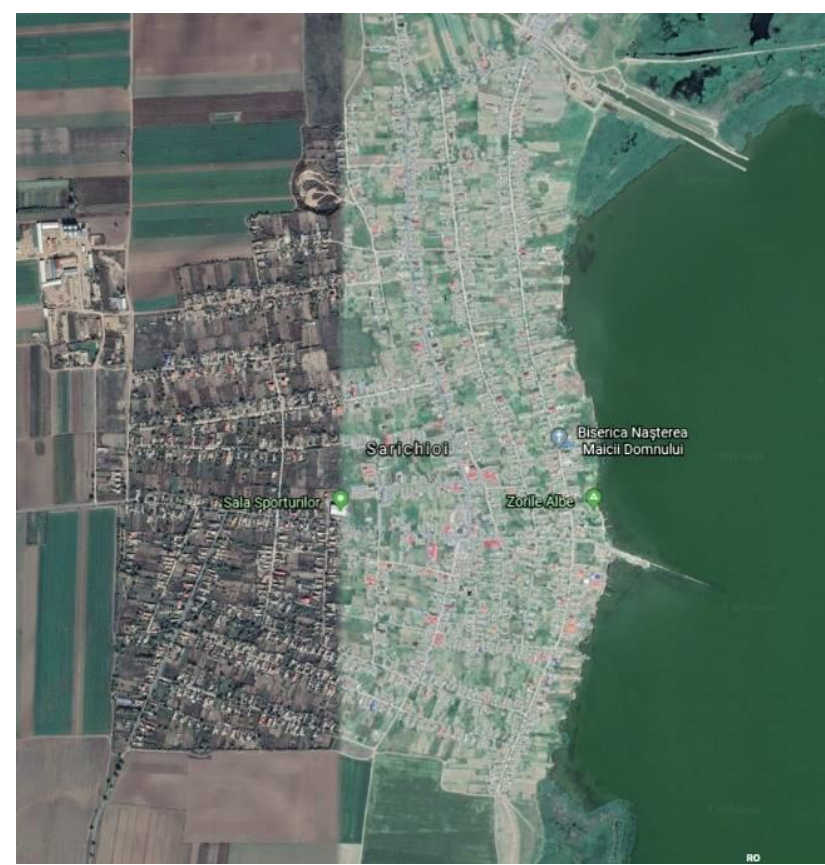

Figure 4. Sarichioi village seen from Google Earth. On the right hand side is the Razim lake.

Other settlements are disposed further away from the lagoons, beyond natural ponds or artificial damming carried out in the 1980s. In these cases, the orientation is towards the ponds or dams but also along the main routes of access (Figure 5). It is the case of the Jurilovca village, where the ponds separate the land from the Golovita lake, situated south from Razim and communicating with the latter.

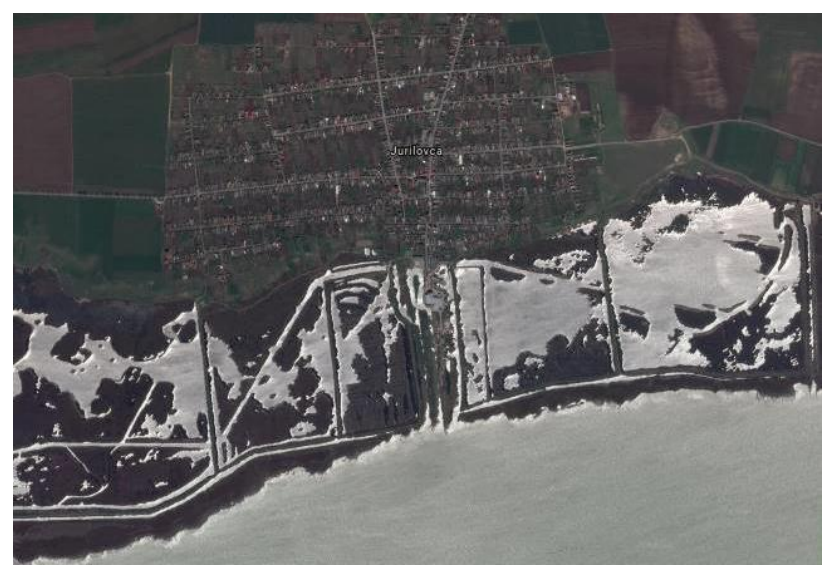

Figure 5. Jurilovca village seen from Google Earth.

\subsection{Building layout}

The geographic conditions in Dobrogea - and Romania in fact provided conservation of energy in buildings as a common sense approach: need and intuition led to the use of some perennial principles applied everywhere in the world, by anonymous craftsmen of the rural built landscape: similar conditions and similar materials lead to similar principle solutions (Dabija, 2006):

- The thermal performance is accomplished by thick walls, low percentage of glazing, shutters and double windows, concentrated thermal mass. 
The general layout of the traditional house is to have porches and windows oriented towards the South (whenever possible, of course) and as much as possible to 'seal' the house against the winds: North-Eastern major wind that blows during the winter and the summer wind, blowing stormy from the South, drying everything around. Sometimes an extra set of spaces is provided, on the exposed sides, sheltering annexes like storage spaces, kitchens, stables, chicken kennels, etc.

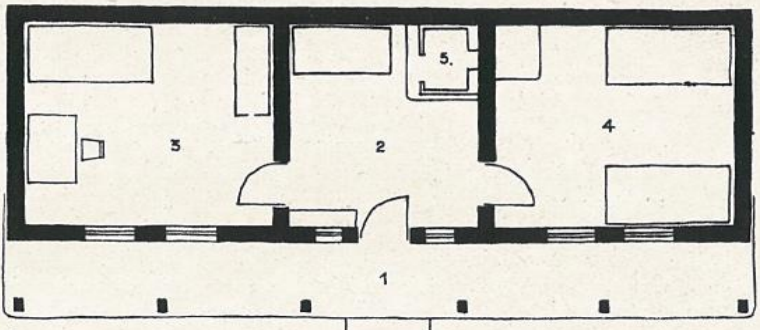

Figure 6. Common house layout in Dobrogea: 1. porch, 2. entrance and room for cooking, 3. guest /the good room, 4. Bedroom, 5. Stove.

The basic house is simple (Figure 6): through the porch, raised on stone foundations, one enters inside in the core of the house, where the main stove is and from where two 'bedrooms' can be found: one that is used by the family and one for the guests; it shelters the best values of the house: sewed pillows and woven carpets, Sunday clothes and all the dowry, kept in a wooden carved chest (Figure 8).
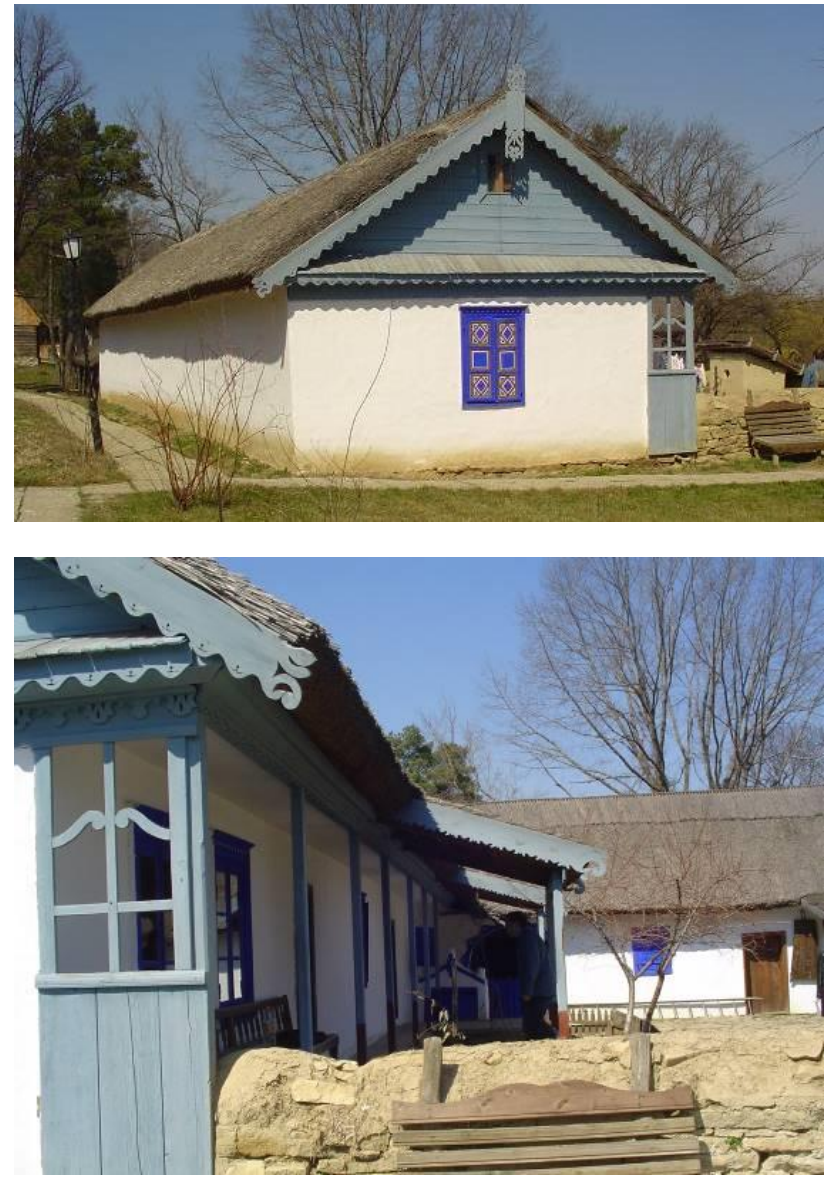

Figure 7. House in Jurilovca - 17th Century (in the Village Museum in Bucharest).
The example of the 17th Century house in Jurilovca probably belonged to richer fishermen: there are more than the three main rooms. The utilitarian annexes (storage, kennel, stable, boat shelter, tools etc) are located against the house, perpendicular to it, sheltering not the house but the courtyard (Figure 7).

The structure and type of windows is the same throughout the whole country: double glazed, with one casement opening outwards and one, inwards to protect against the harsh wind in the winters. When exterior shutters are provided, both sashes open towards the interior (Dabija, 2012) as the wind protection is accomplished by the shutter.
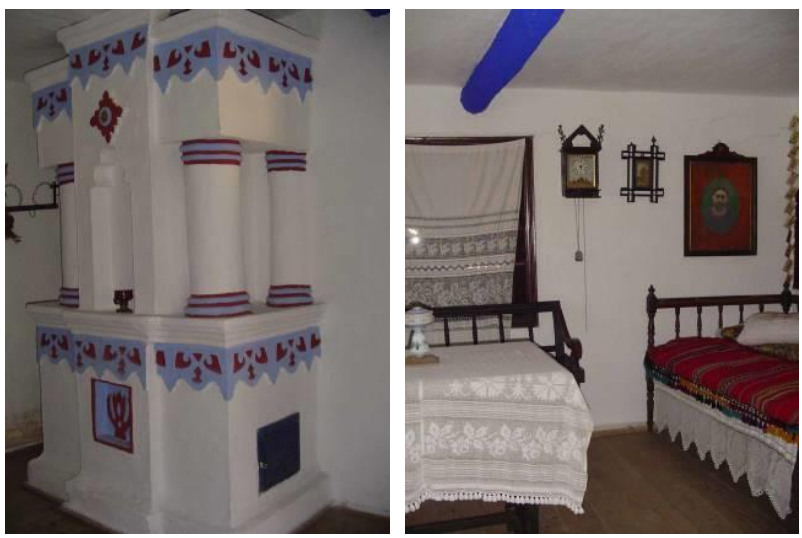

Figure 8. Interior of the 17th Century Jurilovca house. Village Museum, Bucharest.

The roof structure includes large eaves that delimitate open porches. Traditional know-how transmitted to local roofers and builders provide the appropriate depth of the porch as well as the window position and geometry, in order to maximize the sun gain in the winter and to shadow the glass in the summer, thus contributing to the interior comfort of the house.

The porch also serves as an intermediary space for socializing and doing domestic activities in an open, though protected, space.

Simple houses don't have elaborated roofs: two slopes that carry the water away from the roof. Rain and snow slide on the pitched thick thatched roofs or on the barrel tiled roofs with small slopes. The gable walls of adobe or wood is discreetly decorated (Figures 7 and 9) with metal shingles or wood.

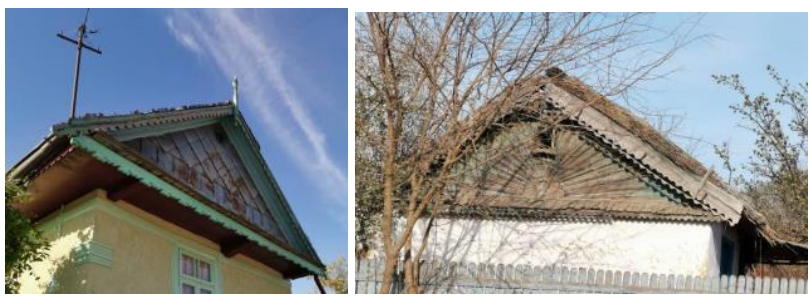

Figure 9. Gable decorated with metal shingles (left) or wood (right).

In the settlements with Russian population, specific features are distinct: the coloured facades and windows. The blue-bluish paint, including the window frames and shutters is still preserved and used in the Dobrogea vernacular houses.

The fence is not high in the traditional architecture of the Dobrogea county; the purpose is to delimitate the individual property - house and courtyard - from the road: people talk to one another, from the road to the porch. Fences are made of adobe, as in Figure 7 or of interlaced wooden birches. 


\subsection{Constructive systems}

The vernacular architecture is based on simple systems, managed and accomplished with the labour force of the family or community. In Dobrogea the use of stone, clay, wood and reed is common for domestic uses.

Stone foundations are provided. Clay mixed with straw, fiber grasses, oakum, chaff, is a common building material for the walls but also for plaster, floors, wall sealants or ovens and stoves with slightly modified compositions. Cast in shapes and dried in the sun, the adobe bricks are used for walls (Stanculescu et al., 1957).

The clay should contain a small quantity of sand and the straw should be chopped, as it results from the trashing. Mixed with muck, the clay is used for the floating of walls, floors and stoves; mixed with chalk, it is used for protecting the exposed surfaces, as it was found to resist weathering. Mixed structures of bricks and clay are sometimes used. The surfaces are finished with chalk.

The roof structure is made of wood. Barrel tiles were often used, fabricated locally but the craft was lost in the 20th Century (Stanculescu et al., 1957).

The wooden elements - the columns of the porch, the beams, the eaves, as well as the decorations or decorated rafters - are coloured, mainly in blue and providing a contrast between the white-ish walls, the thatched roofs and the strong coloured wood.

\subsection{Enhancement criteria}

The vernacular architecture has its roots in the empirical understanding of the laws of nature and in the building approach the local constructors take into consideration all aspects, from the layout and building orientation to the shape of the building, materials and components, in relation with the environmental agents and forces. In other words, the idea is to build with nature, not against it. Bioclimatic architecture has its roots in the common-sense of the vernacular architecture. The most recent requirements in building concepts aim to use local materials and techniques, local labour force, the second matter in a circular economy etc. The local craftsman did this intuitively, as it provided efficiency with minimum investment.

Clay architecture, however, is not a durable system: easy to be destroyed by water, by earthquakes or by a poor maintenance.

More people in the country opted for more resistant buildings and, in the past thirty years, for larger houses, with "imported" (sometimes of a very bad quality) architecture from the cities or from other regions (Figure 10).
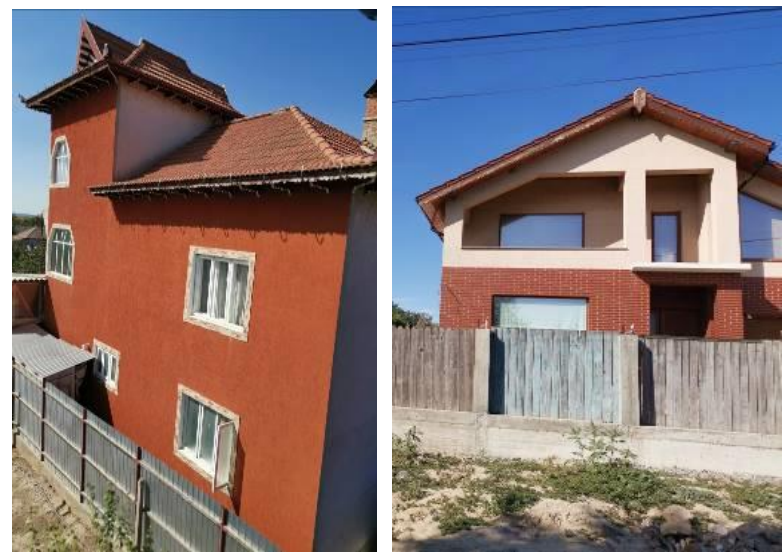

Figure 10. Contemporary houses in Sarichioi village.
Another 'trend' is the thermal rehabilitation fashion of covering the adobe façade walls with a blanket of thermal insulation, as seen in Figure 11.

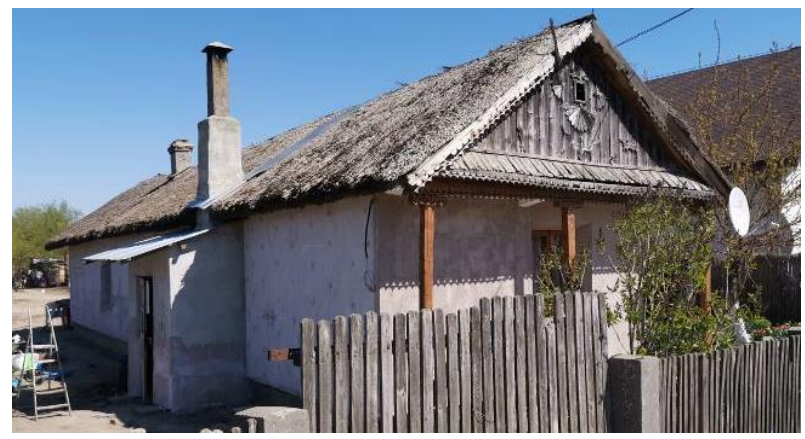

Figure 11. "Thermal rehabilitation" of an adobe house, in Sarichioi.

We do not promote the stone-still attitude in the vernacular architecture but there are limits in interpreting the old. Therefore, new materials and systems that are familiar to the city landscape, should not be used in the rural area or - if not possible otherwise - used wisely. It is the case of an old building that has been extended and modernized with contemporary means but in an obvious respect for the built heritage (Figure 12).

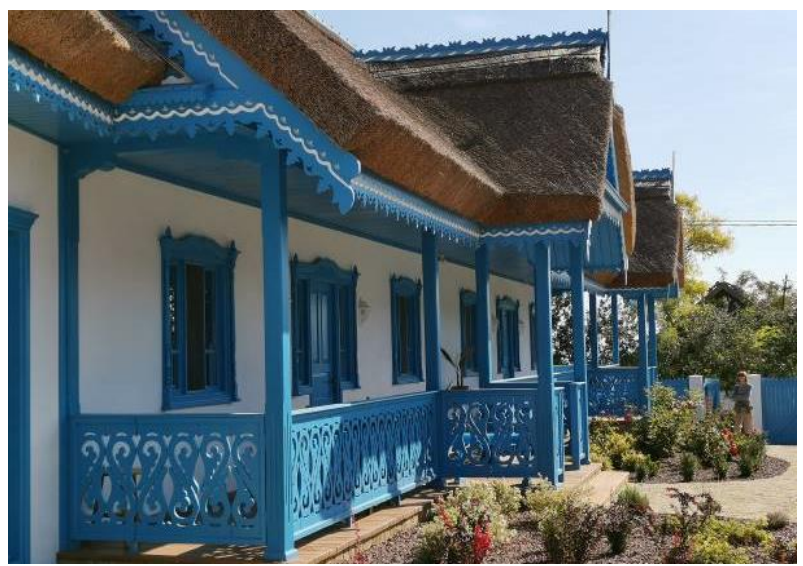

Figure 12. Extension of an old house, Sarichioi village.

Preserving the vernacular patrimony has a long history in Romania: The Village Museum in Bucharest, initiated in the thirties by sociologist and historian, Dimitrie Gusti, was the first and largest museum of ethnography and folklore, where buildings were brought from all regions. It opened around the same time as the Skansen museum in Stockholm. Today, along with the extension of the museum, architects produced guides for interventions, specific for different regions, in order to avoid the bad quality or inappropriate architecture.

\section{THE SOUTH SIDE OF VESUVIUS}

\subsection{Settlement characters}

The Vesuvian territory, delimited by the Vesuvius National Park in the Campania region in the south of Italy, characterized by very high natural and cultural value of the rich testimonies that are preserved and which have conditioned the development of the whole South and East area of Naples. However, in recent decades, unauthorized building, despite the volcanic risk, has seriously invaded the slopes of the volcano suffocating the 
ancient rural villages. The southern slope of Vesuvius, object of our study, presents very poor rural villages compared to the northern slope richer in water and vegetation due to the different orographic features; however, this condition played a role in favour of preserving the authenticity of the old houses because, as they were humble single-storey houses, they were simply abandoned without undergoing any transformation. Over time, the mosaic of the small landowners has become saturated with new illegal constructions in which the descendants of the ancient Vesuvian farmers have moved their residence, downgrading the old houses into warehouse.

Vesuvian vernacular architecture is one of the most important cultural elements in the Campanian rural landscape, it is the product of poor culture and of the need to adapt to the environment by making the best use of the resources it offered. The architecture of the peasant culture and its small 'annexes' is essentially represented by single-family houses, of an agro-pastoral nature, sometimes gathered in small villages where functions are housing, producing and social living. (AA.VV., 2014).

Already in Roman times prior to the 'birth' of Vesuvius, that arose from the explosion of the old volcano with the famous eruption described by Pliny the Elder in 79 AD which destroyed Pompei, Ercolano and Stabia, the Vesuvian area was particularly fertile and productive for the richness of the volcanic soils, the good solar exposure and favourable climatic conditions tempered by the proximity of the sea. (Figure 14) (Langella, 2012).

The fertility of the land always encouraged local inhabitant to build their settlements even on the most impervious and poor slopes of the Vesuvius volcan, so developing typical constructive solutions that are surviving still today. Along the Vesuvian slopes there are paths lined with dry stone walls that climb the mountain to reach the rural settlements that testify the strong integration of the inhabitants in such a difficult, even if fertile, environment. (De Joanna, Passaro, 2017).

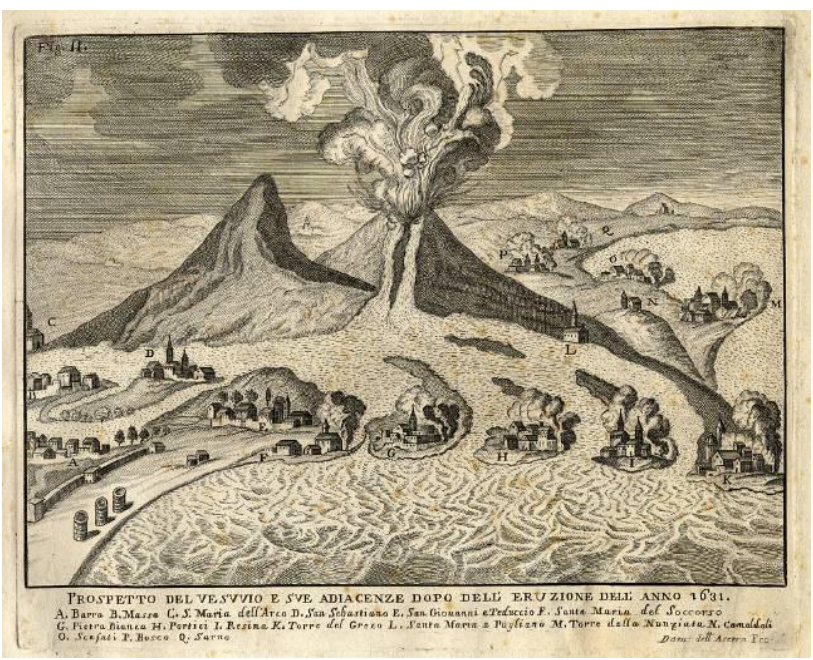

Figure 14. The eruption of Vesuvius in 1631.

\subsection{Resources}

The rural buildings of the southern slope of Vesuvius are characterized by the use of building materials found in the immediate vicinity. The eruptive materials are the consequence of the eruptions of Vesuvius (1281m) which followed one another from 1631 to 1944 (the most recent eruption); almost all the eruptions affected the southern slope, covering it with lava effusions and a layer of lapilli.
The uneven ground and the difficulty of paths made the transport of materials from other places too onerous, therefore quarrying and building in the same place was easier and cheaper. The impervious orography also affects the planimetric development of the buildings; the repeated lava flows determine inclined and steep planes and therefore the houses, generally without foundations, had to be firmly anchored to the lava bank. They supported the load-bearing walls directly on the plain of the ground and on the rock choosing the most accessible and outcropping excavation site but carefully away from the gullies of water outflow.

Historical data on exploitation activities are scarce; in general the excavations were carried out arbitrarily by the inhabitants themselves; approximately in the eighteenth century there were a dozen quarries in the area of the municipalities of Terzigno and in those in the coastal area at the foot of the volcano, the number of quarries increased significantly later in the nineteenth century due to the policy of the Borboni that encouraged the exploitation of resources of the kingdom.

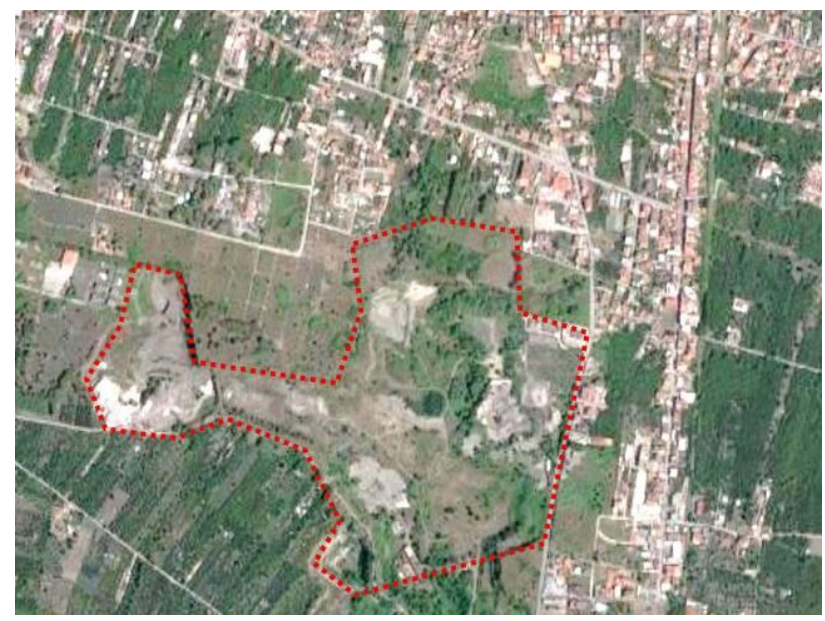

Figure 15. Ranieri quarry in Boccia al Mauro, Terzigno (Naples).

The material was extracted from very superficial fronts, in fact the 'foams' and lavas for the manufacture were extracted just below the layer of lapilli and 'ferrugine (surface layer of the lava flow in the form of loose slag)', that were instead used for the preparation of the mortar. (Figure 15). The 'ferrugine' and the 'foams' are porous and light but, due to the roughness of the structure, they good resistance to mutual sliding between the parts in case of fracture and therefore they have a good resistance to seismic actions; for these characteristics they were used for the construction of the vaults. Finally, the compact lava was extracted in blocks and used in the raw state for the walls, the best quality blocks were used for the corners.

The excavation area became the site of the building and the resulting underground void was used as a cellar where, thanks to the characteristics of temperature, orientation and ventilation, an ideal environment was created for storing wine which was the main source of local economy. (AA.VV., 2014)

\subsection{Rural space layout}

The rural settlements on the South and West sides of Vesuvius are the result of the inhabitants' work of adaptation to the characteristics of the place; priority needs can be summarized in: 
- Optimizing the collection of rainwater, the only source of supply for domestic and irrigation uses given the absence of spring water on the southern slope.

- Obtaining the best conditions for the yield of vineyard and the quality of wine production.

The village in Boccia al Mauro in Terzigno on the southern side of Vesuvius, currently almost completely abandoned, represents an authentic form of settlement, consistent with the site resources and with the needs of farming and housing, while exploiting as better as possible the local characteristics.

The need to collect large quantities of water to irrigate fields and breed animals was of primary importance for the survival of people and the economy. However, the southern slope of Vesuvius is almost completely devoid of a superficial water network due to the cracks in the lava flows that divert the rainwater towards the underground layers, causing more overlapping layers at the different lava stratum (Figure 16).

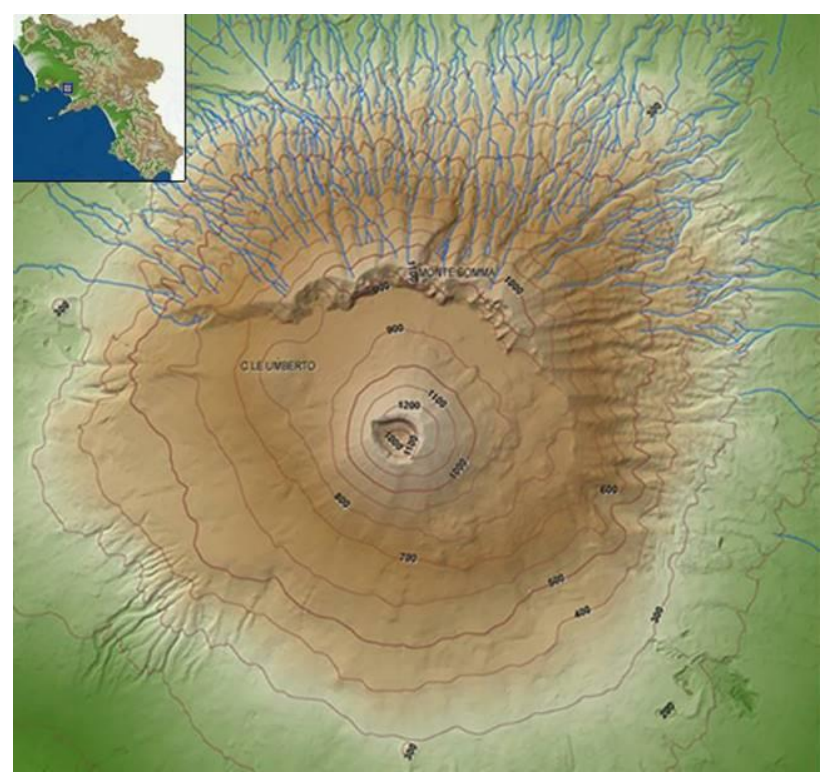

Figure 16. Hydrography of Mount Vesuvius (from: Geological Service and Soil Defence - Campania Region).

In order to adapt to this condition in the Vesuvian rural area, slopes, canals and downpipes have been created to convey the water into cisterns and wells at different levels so that, once the overflow of a tank is reached, the waters flowed to the next one without dispersions. In the bigger settlements a cistern was generally built in the center of the village, in which all the rainwater from the roofs of the houses flowed through clay pipes (di Caterina, 2012) The cisterns could be accessed by means of wells or even from inside the houses by means of small shafts with rudimentary lifting mechanisms. (Figure 17).

The production of wine played a fundamental role in the small economy of the territory and the whole settlement system and the cultivation were aimed at creating the best conditions for the cultivation of vineyards, grape harvesting and wine production.

The cellar was, together with the oven, the main room of the house. It has already been said that the cellar, or "wine cave", occupies the void of the excavation in the lava bank from which the construction material is extracted; here the darkness, the humidity of the soil, left specifically without flooring, and the wood of the barrels determined the optimal conditions for the processing and storage of the wine. Inside the cellar there is a masonry tank in which the grapes were poured from the outside, pressed and then left to ferment. The room had to be oriented to the south to benefit from solar heating, which contributes to the transformation of fructose into alcohol, and had to have numerous vents so that the carbon dioxide produced by the must during fermentation could be dispersed.
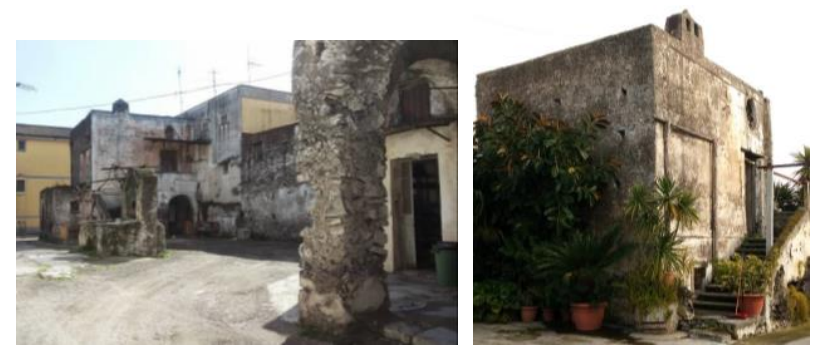

Figure 17 and 18. Village with well and A rural house (Boccia al Mauro, Terzigno).

\subsection{Building layout}

In the village of Boccia al Mauro, established near the Ranieri quarry in Terzigno, there are still ancient rural houses preserved in their original shape and structure; most of them are abandoned or used as deposits. The obsolescence of old buildings, due to the exigence of modern life style, induced the inhabitants to build new modern houses close to the ancient ones, while the older ones where simply disused and therefore they saved from destruction or heavy transformations (Figure 18).

These dwellings are in general constituted by a single room or, at most, two modules joined, they are located at a mezzanine level and at the ground level there is the shelter for the animals, so that the living spaces are raised and isolated from the ground and can profit of a warm air chamber beneath.

In general, the stove without chimney and the washtub are located outdoor on the stair house to keep safe the interior air (di Caterina, 2012).

All the domestic functions are carried out in the same space, where the beds, the few essential furnishings and the table are gathered; a large fireplace is set against the entrance wall, preferably facing south, to benefit from the best exposure to the sun; also the chimney pots have the holes facing south to facilitate the draft of the chimneys by taking advantage of the winter winds from the south-east.

Rural houses of very similar typologies, both constructive and environmental, can be found in the area of Sorrento (Naples) and in the islands of Procida, Ponza, Pantelleria ('dammusi') and in the Aeolian Islands, where they are called different names. The same typology is also found in many villages in Greece and Turkey.

The name of 'dammuso' of Pantelleria derives from the Arabic 'dammus' which means 'vault', indicating the typical domed roofs of these rural buildings; however, the same word can be traced back to the matrix of the Latin term 'domus'; it has the particularity of having oblique perimeter walls, built in this way because mortar was used sparingly and reserved only for the base part. In general we can find many similarities between these simple living models in the Mediterranean: the domed roofs, the presence of the well and the cistern, the external oven, are all elements that are repeated in a very similar way through 
geographic locations, although different and distant. The Aeolian model is distinguished by the addition of a small external loggia made of smooth cylindrical columns ('pulera') and wooden beams (Figures 19 and 20).

Often inside the house or next to the external oven a small well may be found, that draws water directly from the cistern. The kitchen compartment was small and poorly lit and it contained all the tools for preparing food; the cooking place was the wood stove ('fornacella') with two or more 'fire mouths'. In the Vesuvian houses, however, the wood stove was often located outside on the access landing. In one corner of the floor there was a trap door of a small underground space for storing some food and for storing coal.
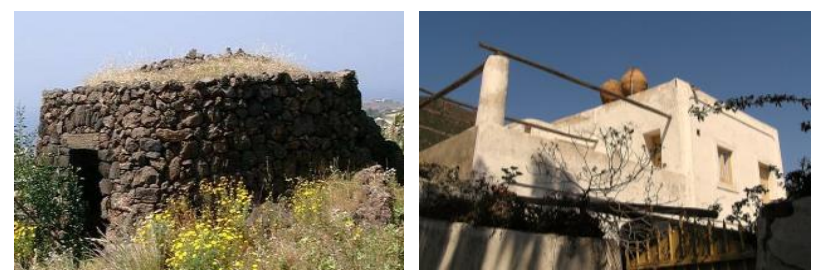

Figure 19 and 20. 'Dammuso' (Pantelleria, Trapani) and Rural Eolian house with 'pulera' (Lipari, Messina).

Typical of the rural house is also the presence of large outdoor spaces facing south, to support outdoor activities. Paved areas, sinks and pergolas are arranged in order to allow washing the laundry, cooking food, playing children and resting; in fact, the temperate climate allowed to spend most of the year outdoors, a picturesque aspect that legitimizes the essentials of the careless interiors furnished with the bare essentials.

The work area and the countryside were often far from the houses and accessible only by pathways and long hours of walking, therefore it was necessary to have small shelters to store tools or to shelter animals and people in case the work or adverse weather conditions prevented returning home in the evening. Depending on whether the shelter was needed only in case of temporary rains or for longer stays, it took on different characters: simple barriers or screens in the case of stops of a few hours, shelters of reeds and branches in the case of stays of a few days while for longer stops real huts were built where to sleep, keep some supplies and especially water. Generally, the latter were built close to a lava rock, they were rather narrow tunnels that have a low and narrow entrance covered with a canopy of shrubs and wooden planks, inside they widen into a single circular space. (Langella, 2012).

\subsection{Constructive systems}

2.5.1 Buiding envelope: The constructive system of the rural houses on the Vesuvius' South slopes consists of lava stone blocks and 'scheggioni' (pyroclastic rock fragments) in a very irregular texture of variable dimensions, depending on the quality of stone that were put in place, raw as well as quarried. The best stone blocks, in terms of shape, dimension and resistance, were used in the low parts of the construction and in the corners, in order to strengthen these parts of the building. In the upper level of the masonry smaller blocks and fragments of 'ferrugine' (less compact and coherent than lava) are employed and the smallest were used for filling empty spaces. Internally the floor is rarely paved in terracotta, in most cases being made with a simple slab of lime, lapilli and tiny fragments of lava foam (Figure 21).
The masonry of the rural house was generally covered with plaster in order to preserve it from the atmospheric agents and to regularize the external surfaces for preventing dusty deposits and plant and animal infestation.

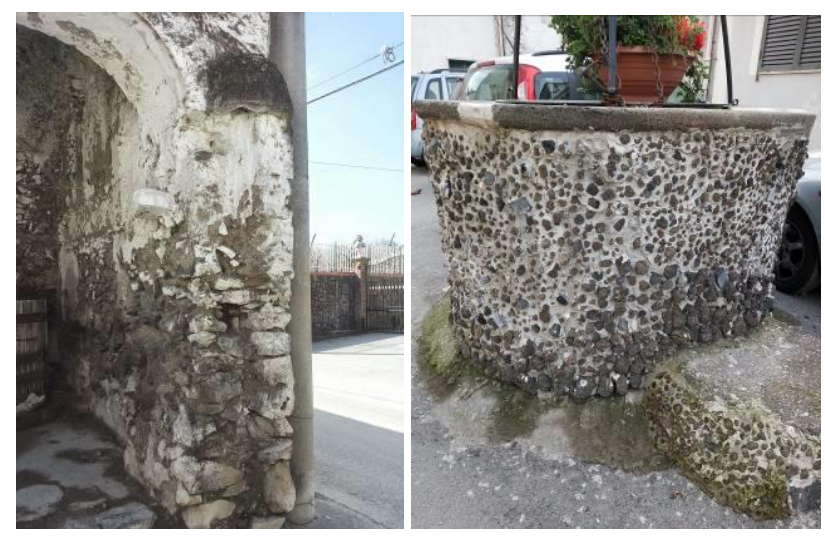

Figure 21. Lava masonry and water well

(Boccia al Mauro, Terzigno).

2.5.2 Openings: The windows and the doors are generally made with a simple wooden lintel or with a flat arch of lava stones and 'ferrugine' or foam. Windows are very few and small. Above the door on the south façade there is always a window that is the only light source, while on the other facades one can find small holes for allowing the ventilation without losing heat; at the basement small holes are created to guarantee ventilation (Figure 18).

2.5.3 Roofs: The roof of most of the rural houses on this side of Vesuvius are characterized by a typical shape of curved extrados which had the fundamental function of collecting rainwater and channeling it through terracotta pipes into the underground tanks, this due to the lack of springs or watercourses. To waterproof the roof the finishing was done with a layer of lapilli that has a silica content that allows to seal the covers. Furthermore, the shape of the extrados and the position of the chimney is designed not to obstruct the flow of water (De Joanna, Passaro, 2017).

\subsection{Enhancement criteria}

Unfortunately, this heritage is still not well known today although it is an authentic testimony of the Arab influences that have left significant and persistent traces in the spread of these types of rural architecture, an excellent example of efficiency and adaptation to the environmental context. (Langella, 2012).

The enhancement of architectural assets is strongly linked to the context which they belong, both people and places, so the net of functions and relationships that rule the settlements in the territorial system must be well known for identifying the most significant factors in the interface between future possible uses and the consistency of the heritage. Similar buildings that I cited, located in the islands of Pantelleria and Lipari, are actually mostly recovered and used as touristic accommodation due to the prevalent vocation of those places to be a summer tourist destination. Inhabitants of the islands take, for their nature and culture, particularly care of their heritage, thus the 'dammusi' are generally restored in the respect of the original layout and constructive structure. The economy in the Vesuvian area does not exploit the enormous resources coming from the geological, naturalist and archeological area. The ancient rural economy is still survived and only in recent years the excellent 
productions, such as apricots, tomatoes and wine, have begun to arise. The rural settlements must be protected and could be part of a development strategy, but it is strictly necessary to officially recognize them as cultural heritage, this means that the municipality must apply the candidacy to be included in the National Register of Historic Rural Landscapes and a plan of recovery and enhancement needs to be done. This historical settlements are spread around the south side of the Vesuvius and could be integrated in a net of infrastructure to promote touristic, cultural and scientific explorations to the quarries, to the Vesuvius slopes and to archeological areas.

\subsection{Conclusions}

The two case studies presented in this article refer to very different contexts in which the availability of local resources and environmental conditions determined the construction choices; they are two different worlds united by primary needs and based on an economy linked to very particular environmental conditions. Both present specific settlement circumstances: the Danube Delta is a 'young' and changing territory, as the marshes still shape the land and water; it is a biosphere reservation and a home for usual and protected species of birds and fish; in the case of the Vesuvian settlements, the difficulty in moving and the lack of water and vegetation determine an apparently inhospitable environment but the fertility of the soil, the good exposure to the sun and the mild climate were the preconditions for having abundant harvests and motivated the farmers to live and cultivate in these places. So what most unites the two villages are the challenges that the inhabitants have undertaken by virtue of productivity above all other advantages. The observations regarding the villages of the Danube Delta in Romania and Vesuvius in Italy lead to outline a criterion in the interventions of recovery of these settlements; rural landscapes are to be considered to all intents and purposes as Cultural Landscapes and, as such, subject to attention by the World Heritage Committee which since 1992 established the category of Cultural Landscapes of the European Community.

This study aims to highlight the need in redevelopment interventions to know not only the rules but mainly the reasons for the constructive and morphological choices to avoid projects that falsely and wrongly propose the vernacular archetypes and above all to have the knowledge for a critical judgment in management the additions and adjustments that are necessary to make these buildings usable still in the modern economy. These constructions are not always suitable for housing because the adaptation to modern standards would be incompatible with conservation requirements: the villages on Vesuvius, for example, typically consist of a single compartment in which all domestic functions took place, there are rarely two-room buildings, they are generally equipped with few and small windows that create a dimly lit indoor environment; in the villages on the Danube Delta the available building materials need maintenance and care and the craftsmen who still master the techniques are disappearing. As in the Vesuvian landscape, windows are small, as they represent ways of heat-losses but, as a response to the rough climate with strong winds, double casements are provided and often shutters.

Last but not least, it is important to remember that the historical reasons for the settlements in these inhospitable places are intimately linked to local resources and therefore any rehabilitation choice can be ethically correct only if it guarantees that the geological nature of the area is preserved and enhanced, the local trades are preserved, the local materials and techniques are employed.

\section{ACKNOWLEDGEMENTS}

The contribution is the result of a common reflection by the authors. Despite this, the first part entitled "The Danube Delta Region" is to be attributed to Ana Maria Dabija and Radu Sfinteș, the second part entitled "The South Side of Vesuvius" is to be attributed to P. De Joanna, A. Passaro and G. Vaccaro.

\section{REFERENCES}

AA.VV., 2014. Architettura rurale nei parchi Nazionali Cilento, Vallo di Diano, Alburni e Vesuvio, MiBAC

CODUL SILVIC / The Silvic Code 2008 (Legea nr. 46/2008) Republicat si Actualizat 2016

Dabija, A. M., 2006.Tradition and innovation in contemporary Romanian architecture Passive and Low Energy Architecture Conference, published in the Conference Proceedings of the PLEA - Geneva 2006

Dabija, A-M., 2012. Influences of Environmental Agents in Architecture Tradition and Innovation. Romania: A Case Study International Conference on Civil Engineering, Architecture and Building Materials, 25-27 mai 2012 Yantai, China, published in Applied Mechanics and Materials

De Joanna P., 2016, Architettura e materiali lapidei. Strategie sostenibili e processi estrattivi, Maggioli Editore, Milano.

De Joanna, P., Passaro, A., 2017. Tools for the enhancement of enclosed spaces of rural heritage in the mediterranean city International conference on conservation of architectural heritage and urban history, Istanbul 13-14 Ottobre 2017.

De Joanna, P., Passaro, A., 2017. Use of stone resources in the Vesuvian area: architecture and landscape, in Building in Mediterranean region. Sustainable technologies and materials for inhabiting: Italy, Morocco, Portugal Tunisia (Francese D. and Passaro A. editors), D'Arco soluzioni per la stampa, Napoli.

di Caterina E., 2012. Architettura Rurale Vesuviana, available at: www.vesuvioweb.com, (21/09/2016).

Langella A., 2012. Le abitazioni rurali alle falde del Vesuvio, parte prima, available at: www.vesuvioweb.com, (21/09/2016).

Langella A., 2012. Le abitazioni rurali alle falde del Vesuvio, parte seconda, available at: www.vesuvioweb.com, $(21 / 09 / 2016)$.

Stanculescu, F., Gheorghiu, A., Stahl, P., Petrescu, P., 1957. Arhitectura populara romaneasca, Dobrogea. 